\title{
Monitoring public health nutrition capacity development
}

Roger Shrimpton ${ }^{1}$, Margaret Miller ${ }^{2}$, Chizuru Nishida ${ }^{3}$, Hélène Delisle ${ }^{4}$, Lenore Spies ${ }^{5}$, Sonia Blaney ${ }^{6}$.

\section{Introduction}

The Comprehensive Implementation Plan on Maternal Infant and Young Child Nutrition (CIP-MIYCN) endorsed by the $65^{\text {th }}$ World Health Assembly (WHA) in 2012 (WHO 2012), includes six global nutrition targets to be achieved by 2025 as well as five actions to support the achievement of the global targets (See Box 1). Action 4 calls upon Member States to identify and map capacity needs, and to include and fund capacity-development in national plans to expand and scale-up nutrition actions. Action 5 calls for a well-defined framework that would allow a harmonized and internationally accepted approach to monitoring progress towards achieving the nutrition targets at both the national and global levels, as well as actions taken to put the MIYCN Plan into practice.

\begin{tabular}{|c|c|}
\hline \multicolumn{2}{|r|}{$\begin{array}{c}\text { Box 1. WHO Maternal Infant and Young Child Nutrition (MIYCN) } \\
\text { Comprehensive Implementation Plan }\end{array}$} \\
\hline $\begin{array}{l}\text { Nutrition } \\
\text { Targets }\end{array}$ & $\begin{array}{l}\text { 1 A 40\% reduction of the global number of children under five who are stunted } \\
2 \text { A } 50 \% \text { reduction of anaemia in women of reproductive age } \\
3 \text { A 30\% reduction of low birth weight } \\
4 \text { No increase in childhood overweight } \\
5 \text { Increase the rate of exclusive breastfeeding in the first six months up to at least } 50 \% \\
6 \text { Reduce and maintain childhood wasting to less than } 5 \%\end{array}$ \\
\hline $\begin{array}{l}\text { Nutrition } \\
\text { Actions }\end{array}$ & $\begin{array}{l}1 \text { Create a supportive environment for the implementation of comprehensive food and } \\
\text { nutrition policies } \\
2 \text { Include all required effective health interventions with an impact on nutrition in national } \\
\text { nutrition plans. } \\
3 \text { Stimulate development policies and programmes outside the health sector that } \\
\text { recognize and include nutrition. } \\
4 \text { Provide sufficient human and financial resources for the implementation of nutrition } \\
\text { interventions. } \\
5 \text { Monitor and evaluate the implementation of policies and programmes }\end{array}$ \\
\hline
\end{tabular}

A UN Decade of Action on Nutrition (2016-2025) has been declared (UN 2016) which endorses the Rome Declaration on Nutrition (FAO/WHO 2014.) as well as the Framework for Action (FAO/WHO 2014) adopted at the Second International

\footnotetext{
${ }^{1}$ Adjunct Professor, Dept. of Global Community Health and Behavioral Sciences, Tulane School of Public Health and Tropical Medicine, New Orleans, USA.

${ }^{2}$ Senior Research Manager, Public Health Discipline, School of Medicine and Health Sciences, Edith Cowan University, Perth, Australia.

${ }^{3}$ Coordinator, Nutrition Policy and Scientific Advice Unit, Department of Nutrition for Health and Development, World Health Organization, Geneva, Switzerland

${ }^{4}$ Professor Emeritus, Département de nutrition, Faculté de Médecine, Université de Montréal, Montréal, QC, Canada:

${ }^{5}$ Director: Integrated Nutrition Programme, Kwazulu-Natal Department of Health, Pietermaritzburg, South Africa

${ }^{6}$ Adjunct Professor, École des sciences des aliments, de nutrition et d'études familiales, Faculté des sciences de la santé et des services communautaires, Université de Moncton,18 avenue AntonineMaillet, Moncton, New Brunswick, Canada, E1A 3 E9.
} 
Conference on Nutrition (ICN2) jointly organized by FAO and WHO in 2014. The ICN2 Rome Declaration reaffirmed the commitments of the CIP-MIYCN and the global nutrition targets as well as the WHO Global Action Plan for the prevention and control of non-communicable diseases 2013-2020 together with diet-related NCD targets which were among the global NCD targets endorsed by the $66^{\text {th }}$ WHA in 2013. The UN General Assembly declaration in 2015 also acknowledged the importance of reaching Sustainable Development Goal 2, which aims to end hunger, achieve food security and improved nutrition and promote sustainable agriculture. The ICN2 Framework for Action has 60 recommendations, of which number 5 is to improve the availability, quality and quantity, coverage and management of multisectoral information systems related to food and nutrition for improved policy development and accountability. WHO is requested to report biannually to WHA on the progress of implementing ICN2 commitments. Furthermore, WHO and FAO are requested to report once every two years to the UN General Assembly on progress being made with the implementation of the work programme of the Decade of Action on Nutrition, which will be first presented at the General Assembly in 2018.

A set of indicators for monitoring the achievement of the 6 global nutrition targets were requested by Member States at the $65^{\text {th }}$ WHA in 2012. A series of consultations has led to a paper being developed (WHO 2014) which proposed and described in detail a core set of 21 indicators (see Box 2) to be included for the Global Nutrition Monitoring Framework (GNMF) developed to monitor the progress in achieving the global nutrition targets, as well as an extended set of optional indicators in an annex, from which countries can draw to design national nutrition surveillance systems fitting their specific epidemiological patterns and programme decisions

\begin{tabular}{|c|c|}
\hline & Box 2. The Core Set of MIYCN Indicators \\
\hline Prir & lary Outcome Indicators \\
\hline 1 & $\begin{array}{l}\text { Percentage of children under } 5 \text { years of age whose height for age is below -2 standard } \\
\text { deviations (SD) from the median of the WHO Child Growth Standard }\end{array}$ \\
\hline 2 & Percentage of pregnant women ages $15-49$ years with a haemoglobin $<11 \mathrm{~g} / \mathrm{dl}$ \\
\hline & Percentage of non-pregnant women ages $15-49$ years with a haemoglobin $<12$ g/ \\
\hline 4 & $\begin{array}{l}\text { Percentage of live births that weigh }<2,500 \mathrm{~g} \text { out of the total of live births during the same } \\
\text { time period }\end{array}$ \\
\hline 5 & $\begin{array}{l}\text { Percentage of children under } 5 \text { years of age whose weight for height is >2SD of the } \\
\text { median of the WHO Child Growth Standards }\end{array}$ \\
\hline 6 & Proportion of infants $0-5$ months of age who are fed exclusively with breast milk \\
\hline & $\begin{array}{l}\text { Percentage of children under } 5 \text { years of age whose weight for height is below - } 2 \text { SD of the } \\
\text { median of the WHO Child Growth Standards }\end{array}$ \\
\hline Inte & rmediate Outcome Indicators \\
\hline 8 & Prevalence of diarrhoea in children $<5 y$ \\
\hline 9 & Percentage of women aged 15-49 with low body mass index $(<18.5)$ \\
\hline 10 & $\begin{array}{l}\text { Number births during a given reference period to women aged } 15-19 y / 1000 \text { females aged } \\
15-19 \text { years }\end{array}$ \\
\hline 11 & Proportion of overweight and obese women >18-49y (BMI $\geq 25)$ \\
\hline 12 & $\begin{array}{l}\text { Proportion of overweight in school-age children and adolescents 5-18y (BMI for age } \\
>1 S D \text { ) }\end{array}$ \\
\hline Pro & cess Indicators \\
\hline 13 & Proportion of children 6-23m who receive minimum acceptable diet \\
\hline 14 & Proportion of population using safely managed drinking service \\
\hline 15 & Proportion of population using safely managed sanitation service \\
\hline 16 & Proportion of pregnant women receiving iron and folic acid supplements \\
\hline 17 & Percentage of births in baby friendly facilities \\
\hline
\end{tabular}




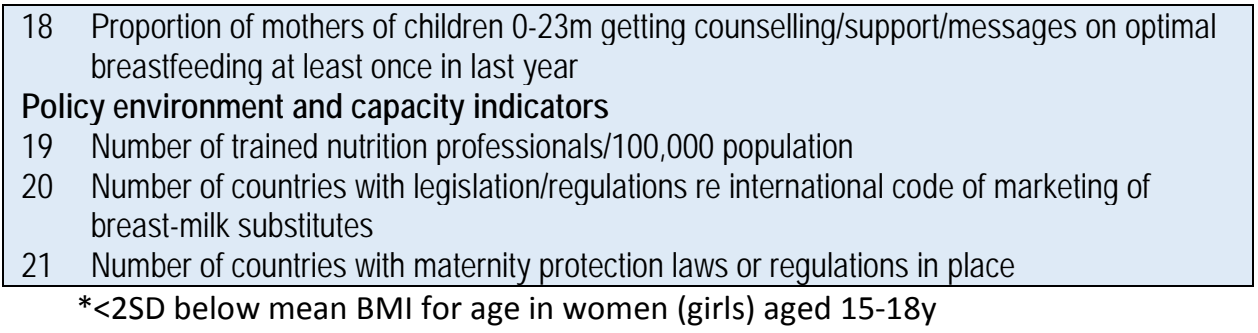

The indicator for the "human resources" dimension of Action 4 of CIP-MIYCN, included in the GNMF is currently described as the "number of trained nutrition professional /100,000 population”. This indicator, together with several other indicators, is currently being further reviewed and operationalized by a Technical Expert Advisory Group on Nutrition Monitoring (TEAM) established jointly by WHO and UNICEF in 2015, with the support and contributions from the Capacity Building Working Group of the World Public Health Nutrition Association (WPHNA).

The purpose of this paper is to contribute to the discussion on how to define "public health nutrition" capacity which will be required to effectively implement and scale-up actions in countries to achieve the global targets to address malnutrition in all its forms which will ultimately contribute to the achievement of the Sustainable Development Goals.

What "human resources" are needed to implement essential nutrition actions? Issues of "capacity development” and "management" of nutrition programmes have not been systematically reviewed in many countries. The Landscape Analysis conducted in nine Sub-Saharan countries between 2008 and 2011 (Trubswasser et al 2012) as well as many other countries outside of Africa, including those in the Americas and Asia (Nishida et al 2009), found that although national nutrition policies often existed, in most places they still needed to translate those policies into effective programmatic actions. Furthermore, human resource capacity for public health nutrition action was largely lacking. But it is not only in Africa, The Americas and Asia that this situation exists, also in Europe a study in seven countries (Kugelberg et al 2012) found that supportive policy environments were largely lacking, with fragmented organizational structures and a workforce that is not cohesive enough to implement public health nutrition strategies. The first Global Nutrition Policy Review carried out by WHO during 2009 - 2010 also found a woeful state of affairs, since although most countries have policies and programmes, most of these having gaps either in their design, content and/or implementation (WHO 2013). This situation is no surprise perhaps as public health nutrition is still a young science (James 1999), and only in the last few decades have the public health dimensions of human nutrition "across the life course" and in addressing the "double burden" become better understood (Herman et al 2014). The World Bank only began to discuss ways that programme managers in governments could identify and deal with nutrition issues around the beginning of the millennium (Heaver 2002).

Since its inception six years ago, the WPHNA Capacity Building Working Group has published a number of papers attempting to better define what nutrition capacity is needed and how to build it. The focus of these efforts has been on public health nutrition (PHN) rather than clinically oriented dietetics, recognizing that the growing 
need is for population based and promotional preventive actions rather than curative interventions for individuals in order to address the increasing global public health problem of the double burden of malnutrition. A competency framework was first developed (Hughes et al 2012) which described the core functions of PHN practice, and the work done at different levels of the public health system. The framework organizes 18 clusters of competency units arranged in four layers with the higher level more related to practice of showing how and doing, and the lower levels more to cognition or knowing what and how. Subsequently a nutrition capacity assessment framework was proposed (Shrimpton et al 2013) to guide the systematic assessment of capacity development needs at system, organizational, workforce and community levels.

How to assure the quality of a workforce for scaling up nutrition programmes in lowand middle-income countries (LMICs) has been another concern (Shrimpton et al, 2016) and a proposed workforce structure agreed to as per Figure 1. The front-line health professionals including doctors, nurses, midwives, and community health workers are the ones that actually implement and/or deliver most nutrition interventions, and may also provide support to other non-health actors, including teachers and agriculture extension workers as examples. At the lower level of the health system, typically at district level, capacity building is proposed for the front-line health professionals through in-service training, that should be largely provided by a Public Health Nutritionist.

Nutrition has to become everybody's business, but somebody has to be responsible for ensuring effective implementation of essential nutrition actions, and that is the proposed role of the PHN manager for the district. This PHN manager should not only be responsible for the capacity building of front line worker, but also the use of nutrition information systems to ensure that the district nutrition services are working well. In service training of these PHN managers is urgently needed if effective nutrition programmes are to be scaled up (Delisle et al 2017).

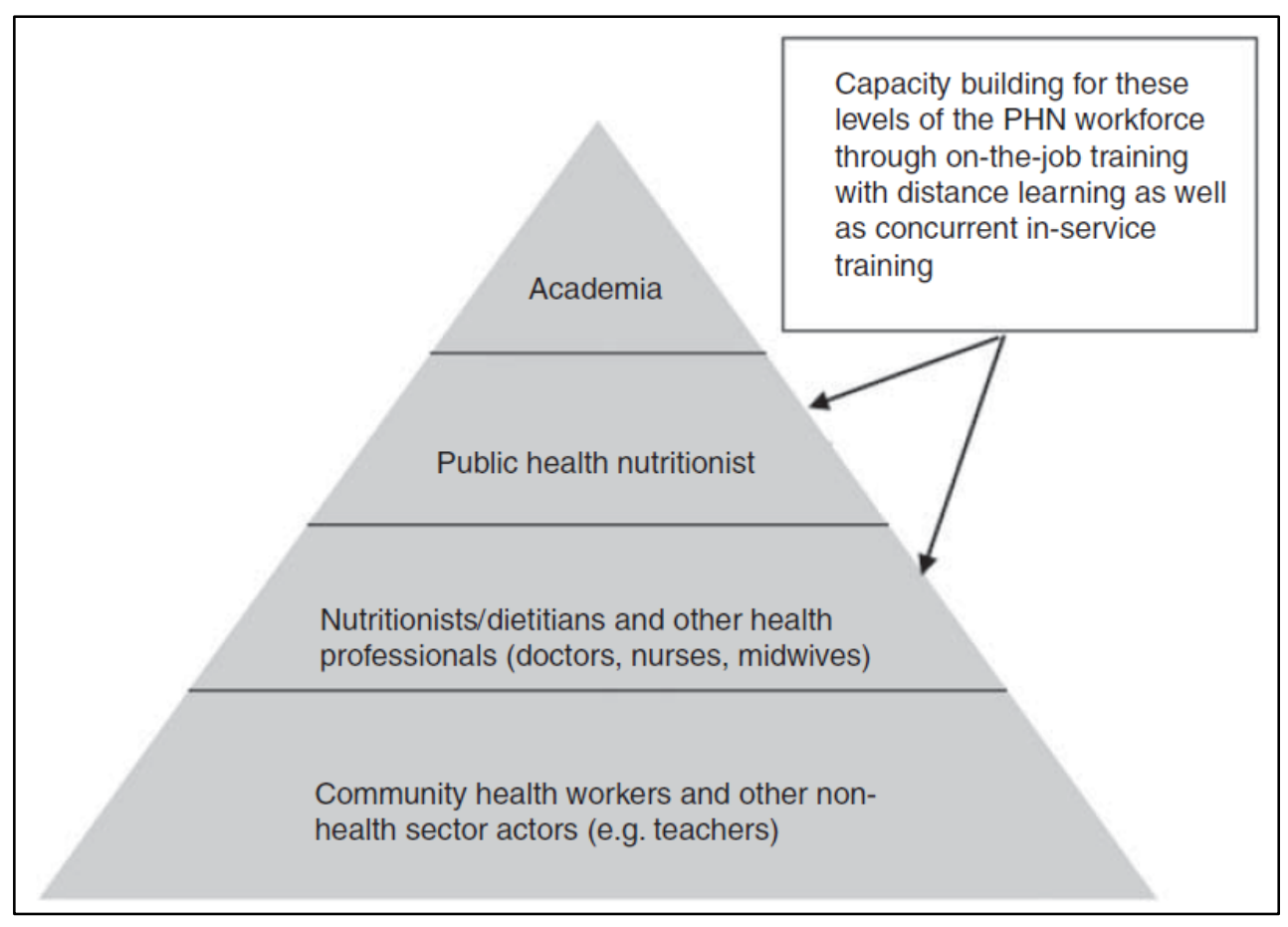


Figure 1 Multi-layered public health nutrition workforce development (Shrimpton et al 2016)

The organization of community health and nutrition programmes is a critical factor for ensuring high coverage of preventive actions that form the crux of PHN. Effectiveness is more likely to be possible through community-based nutrition programmes (CBNP) than "clinic based" programmes, because contact with care-givers is typically more frequent and consistent (Mason et al 2006). The typical structure of a CBNP is shown in Figure 2, and has a "facilitator" from a service delivery channel, typically the health sector, who provides supervision, training, information and support to community based "mobilizers" who are from and operate in their community. The mobilizers, or community health and nutrition workers (CHNWs) typically provide dietary and infant and young child feeding counselling, growth monitoring, and micronutrient supplementations to families with mothers and children in their neighbourhood, as well as helping with their referral to the health centre for treatment of illness as needed. The typical ratios of both facilitators /mobilizers and mobilizers/families is between 1 per 10 to twenty for both. So that one facilitator is needed for every 200-400 families, depending on local conditions.

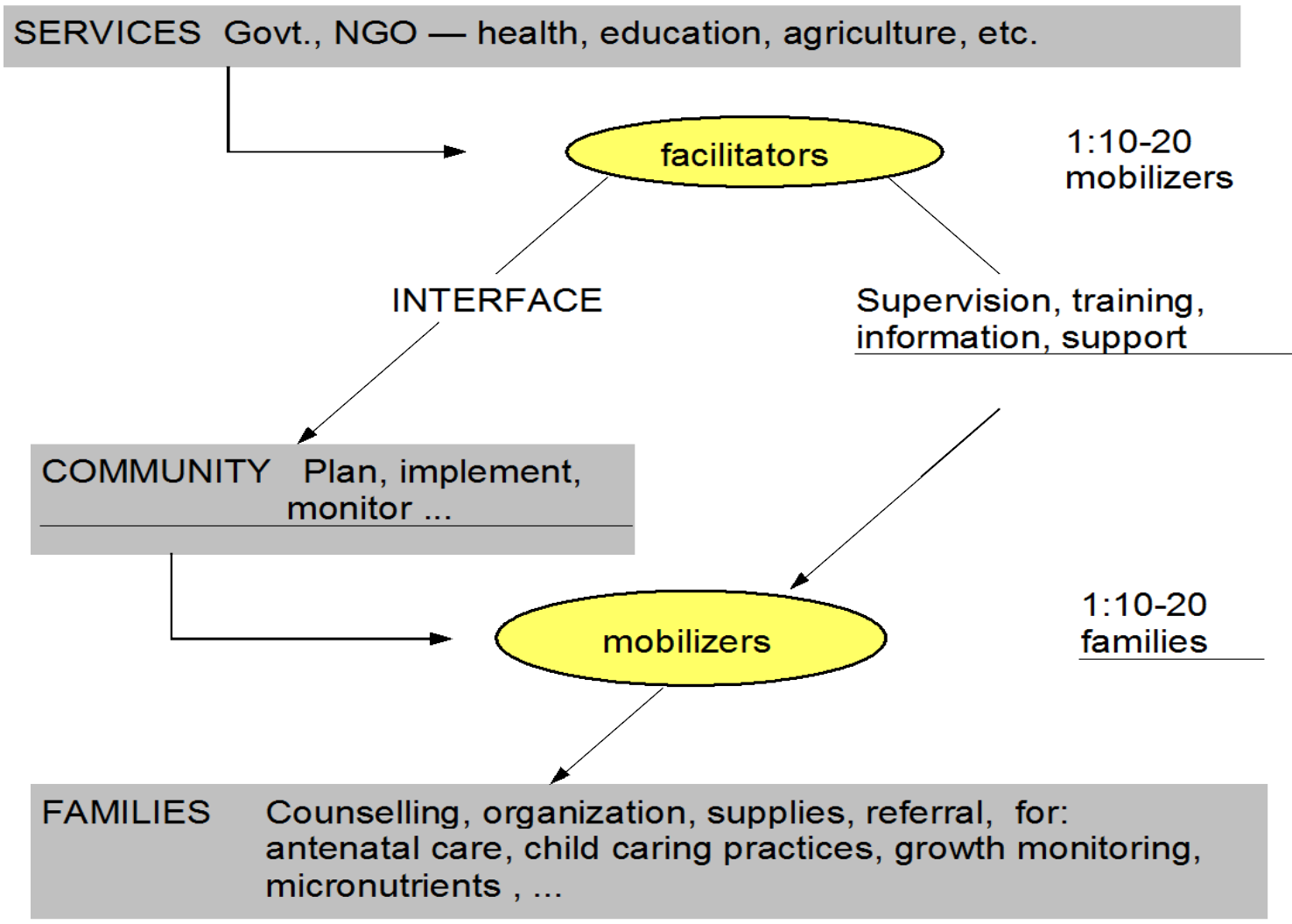

Figure 2. The general structure of community based nutrition programmes. Based on Thailand's Adapted from Tontisirin, 1996 (Mason et al 2006)

More recent orientation from WHO emphasizes the importance of coverage and resource intensity of CBNP that reach out into the community and operate through CHNWs (WHO 2013). The CBNP should presumably be implementing the essential nutrition actions (ENA) currently recommended by WHO as part of the efforts in 
implementing the CIP-MICYN. Experience from programmes from previous decades with more limited packages of interventions suggests that in order to accelerate the reduction of child undernutrition around $30 \mathrm{CHNWs} / 1000$ households are needed (see Figure 3).

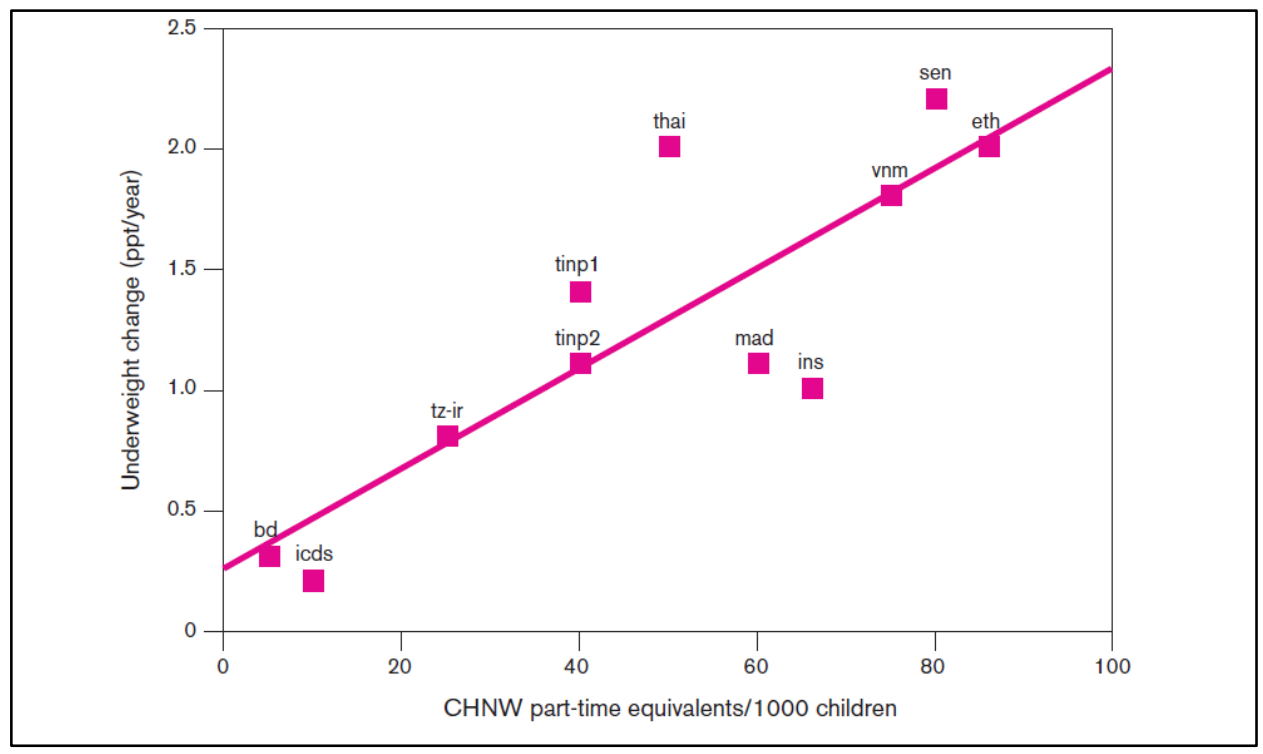

Figure 3. Rate of reduction of child underweight by programme intensity (WHO 2013)

Sufficient coverage of interventions is required in the neediest segments of the population if the reduction of the undernutrition levels of infants and young children is to be accelerated. If this intensity of resources is not ensured at sufficient coverage of the neediest sectors of the population, then no acceleration will be achieved and the programme resources will be wasted.

\section{How should we measure and monitor nutrition capacity?}

We need to measure nutrition capacity both at the system/ organizational level as well as at the workforce/community levels. Capacity at the system and organizational levels are reflections of the strength of nutrition governance (Engesveen et al 2009) which includes the existence of national nutrition plans and policies that are budgeted and part of national development plans, with coordination mechanisms and regular nutrition monitoring and surveillance. One the five action points identified as an imperative for scaling up nutrition action by the World Bank and UNICEF at the turn of the millennium was to systematically use information for decision making (Gillespie et al 2003). The notion of keeping the nutrition situation under "surveillance” was born at the World Food Conference in 1974, and the classic document describing such systems was published by WHO in 1984 (WHO 1984). Then the focus was more on predicting famines than managing programmes aimed at tackling the double burden of malnutrition. A survey in 2014 identified just 31 national nutrition surveillance systems (Friedman 2014), of which complete information regarding key stakeholders, design, status and examples of reports was only available for 16 such systems. The 2016 Global Nutrition Report has called for a "data revolution” in nutrition (IFPRI 2016), confirming that it really is time to revisit and revitalize nutrition information and monitoring 
systems. The existence of a food and nutrition information system must surely be one of the nutrition policy and environment capacity indicators.

To undertake comprehensive monitoring of the nutrition capacity at the workforce and community level, the currently proposed indicator of the number of nutrition

professionals per 100 thousand population would not be enough on its own. A national nutrition workforce strategy and implementation plan has to be an essential element of any national nutrition plan (Mucha and Tharaney 2013). Such a strategy must clearly define the cadres of workers that need nutrition competencies, knowledge and skills as well as defining their job descriptions and accountabilities structures. All such "workers" need to be "put on the same page" with regard to their nutrition knowledge, by updating and harmonizing all "pre-service”, "in service” and "lifelong” learning. Furthermore, there should be a clear accountability of implementing the capacity building locally, regularly and sustainably to ensure the required and quality trainings are delivered. In order to develop such a workforce strategy a capacity assessment should be carried out as a baseline. Some instruments have already been developed to undertake such assessment (SPRING 2014).

\section{Conclusions}

Today we have an unprecedented momentum for nutrition as it is high on the political agenda of Member States and of the international community, following the Second International Conference on Nutrition (ICN2) in 2014 which subsequently transformed to the UN General Assembly's proclamation of the Decade of Action on Nutrition (2016 - 2025). The Decade of Action implementation plan issued recently calls Member States and their partners to reiterate and declare SMART commitments which will be monitored closely for implementation and accountability purposes.

Development and implementation of a national nutrition workforce strategy should be one such SMART commitment. The implementation of a national nutrition workforce strategy should then be measured through multiple indicators, such as the number of front line workers at both the facility and the community level (be they health professionals, teachers, agriculture extension workers or community members), and whether they have had "nutrition training", and if possible of what nature that training was. Furthermore, there must be some indicators of system/organizational capacity, including a food and nutrition information system. Lack of indicators to monitor nutrition capacities in countries is a critical gap in implementing and delivering effective actions to achieve the global nutrition and diet-related NCD targets as well as SDGs. It may be that no country has this information readily available at present, but unless we call for those data and information, national nutrition capacities which are critical component of the nutrition governance to achieve the world free from hunger and malnutrition in all its forms, will not be measured, monitored and developed. To this end, the inclusion of an indicator on nutrition capacity in the GNMF is a good opportunity and starting point to increase awareness of the importance and need for further expansion of nutrition capacity indicators and their monitoring in countries. 


\section{References}

Delisle H, Shrimpton R, Blaney S, Du Plessis L, Atwood S, Sanders D, Margetts B. Capacity-building for a strong public health nutrition workforce in low resource countries. Bull World Health Organ. 2017. 95: 385-388

Engesveen K, Nishida C, Prudhon C, Shrimpton R (2009) Assessing countries' commitment to accelerate nutrition action demonstrated in PRSPs, UNDAFs and through nutrition governance. SCN NEWS 37: 10-16.

Friedman G. 2014. Review of National Nutrition Surveillance Systems. Washington DC: FHI360/FANTA http://www.fantaproject.org/monitoring-and-evaluation/nutritionsurveillance-systems

Gillespie S, McLachlan M, Shrimpton R. 2003. Combatting malnutrition: Time to Act. Washington: The World Bank.

Heaver R. 2002. Improving Nutrition: Issues in management and capacity development. Health and Nutrition (HNP) Discussion Paper. Washington: The World Bank

Herman DR, Baer MT, Adams E, Cunningham-Sabo L, Duran N, Johnson DR, Yakos E. 2014. Life Course Perspective: Evidence for the role of nutrition. Matern Child Health J 18: 450-416

Hughes R, Shrimpton R, Recine E, Margetts B. Empowering our profession. [Commentary] World Nutrition February 2012, 3, 2: 3-54

IFPRI 2016. Global Nutrition Report 2016: From Promise to Impact: Ending Malnutrition by 2030. Washington, DC: International Food Policy Research Institute.

James, WPT. 1999. Historical perspective. Pp 3-12, in Human Nutrition and Dietetics 10th Edition, Garrow JS, James WPT, Ralph A, Eds. Churchill Livingstone: Edinburgh.

Kugelberg S, Jonsdottir S, Faxelid E, Jönsson K, Fox A, Thorsdottir I, Yngve A. 2012. Public health nutrition workforce development in seven European countries: constraining and enabling factors. Public Health Nutr. 15(11):1989-98.

Mason JB, Sanders D, Musgrove P, Soekirman, Galloway R. 2006. Community Health and Nutrition Programmes. Chapter 56 In: Disease Control Priorities in Developing Countries, 2nd edition Edited by Dean T Jamison, et el. Washington (DC): World Bank

Mucha N and Tharaney M 2013. Strengthening human capacity to scale up nutrition. Bread for the World Institute/Helen Keller International

Nishida C, Shrimpton R, Darnton-Hill I. 2009. Landscape Analysis on countries' readiness to accelerate action in nutrition. SCN News 37: 4-9

Shrimpton R, Hughes R, Recine E, Mason J, Sanders, D, Marks G, and Margetts B. 2013 Nutrition capacity development: a practice framework. Public Health Nutrition 17(3):682-8.

Shrimpton R, du Plessis LM, Delisle H, Blaney S, Atwood SJ, Sanders D, Margetts B, Hughes R. 2016. Public health nutrition capacity: assuring the quality of workforce 
preparation for scaling up nutrition programmes. Public Health Nutrition. 19(11):2090100.

SPRING 2014. Nutrition workforce mapping toolkit. Arlington, VA: USAID.

Trubswasser U, Nishida C, Engesveen K, Coulibaly-Zerbo F. 2012. Landscape Analysis - Assessing countries readiness to scale up nutrition actions in the WHO African region. AJFAND 12(4): 6260-6273

UN 2016. United Nations Decade of Action on Nutrition (2016-2025). New York: United Nations.

WHO 1984. Nutritional surveillance. (JB Mason, JP Habicht, H Tabatabai, V Valverde). Geneva: World Health Organization.

WHO 2012. Comprehensive implementation plan on maternal, infant and young child nutrition. Geneva: World Health Organization

WHO 2013. Essential Nutrition Actions: Improving maternal, newborn, infant and young child health and nutrition. Geneva: World Health Organization.

WHO. 2013. Global nutrition policy review: what does it take to scale up nutrition action? Geneva: World Health Organization.

WHO 2014. Indicators for the Global Monitoring Framework on Maternal, Infant, and Young Child Nutrition (24 November 2014) Geneva: World Health Organization. http://www.who.int/nutrition/topics/proposed_indicators_framework/en/

WH0 2015 Maternal Infant and young child nutrition: development of a core set of indicators. Report by the Secretariat. World Health Assembly Agenda Item A68/9. http://apps.who.int/gb/ebwha/pdf_files/WHA68/A68_9-en.pdf?ua=1

WHO 2016. Maternal Infant and young child nutrition. Report by the Secretariat. World Health Assembly Agenda Item A69/7.

http://apps.who.int/gb/ebwha/pdf_files/WHA69/A69_7-en.pdf?ua=1\&ua=1 